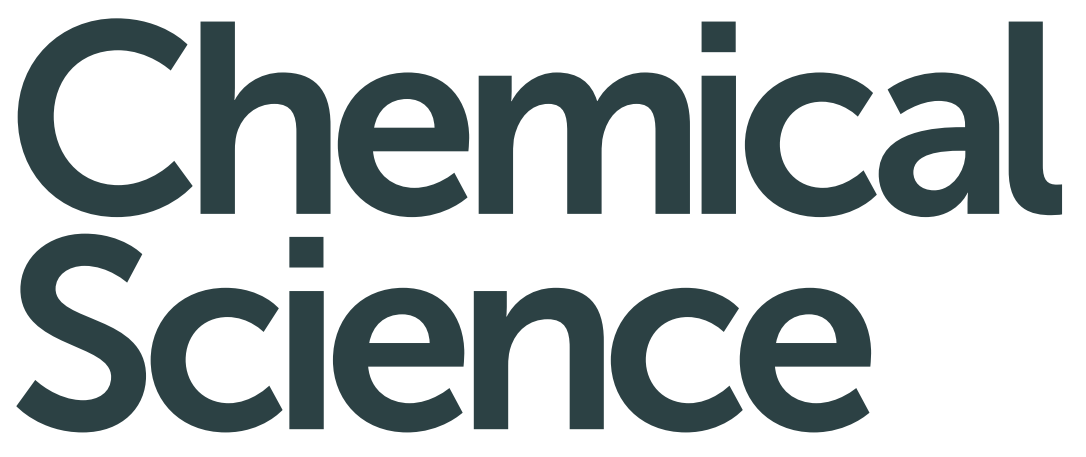

rsc.li/chemical-science

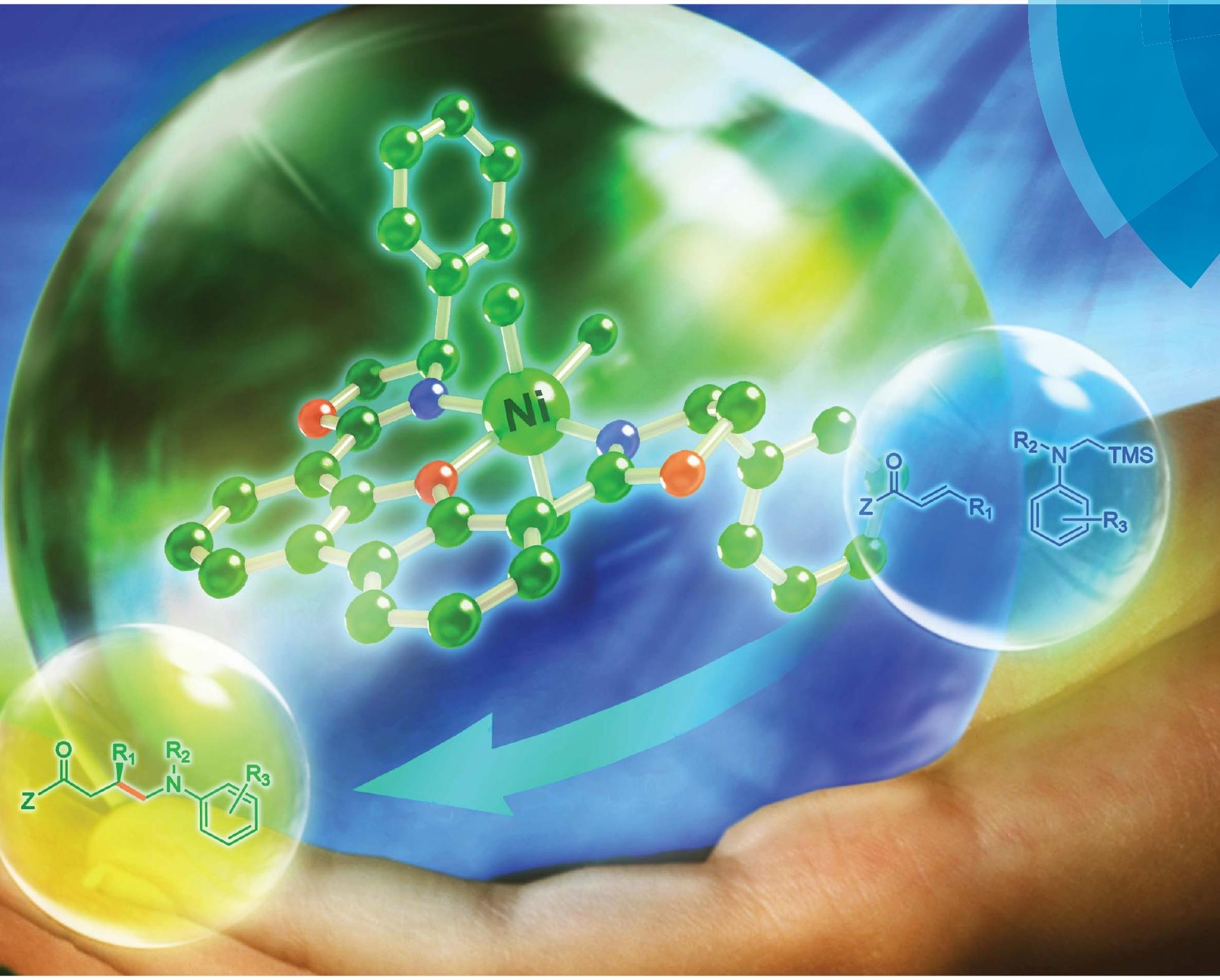

ISSN 2041-6539
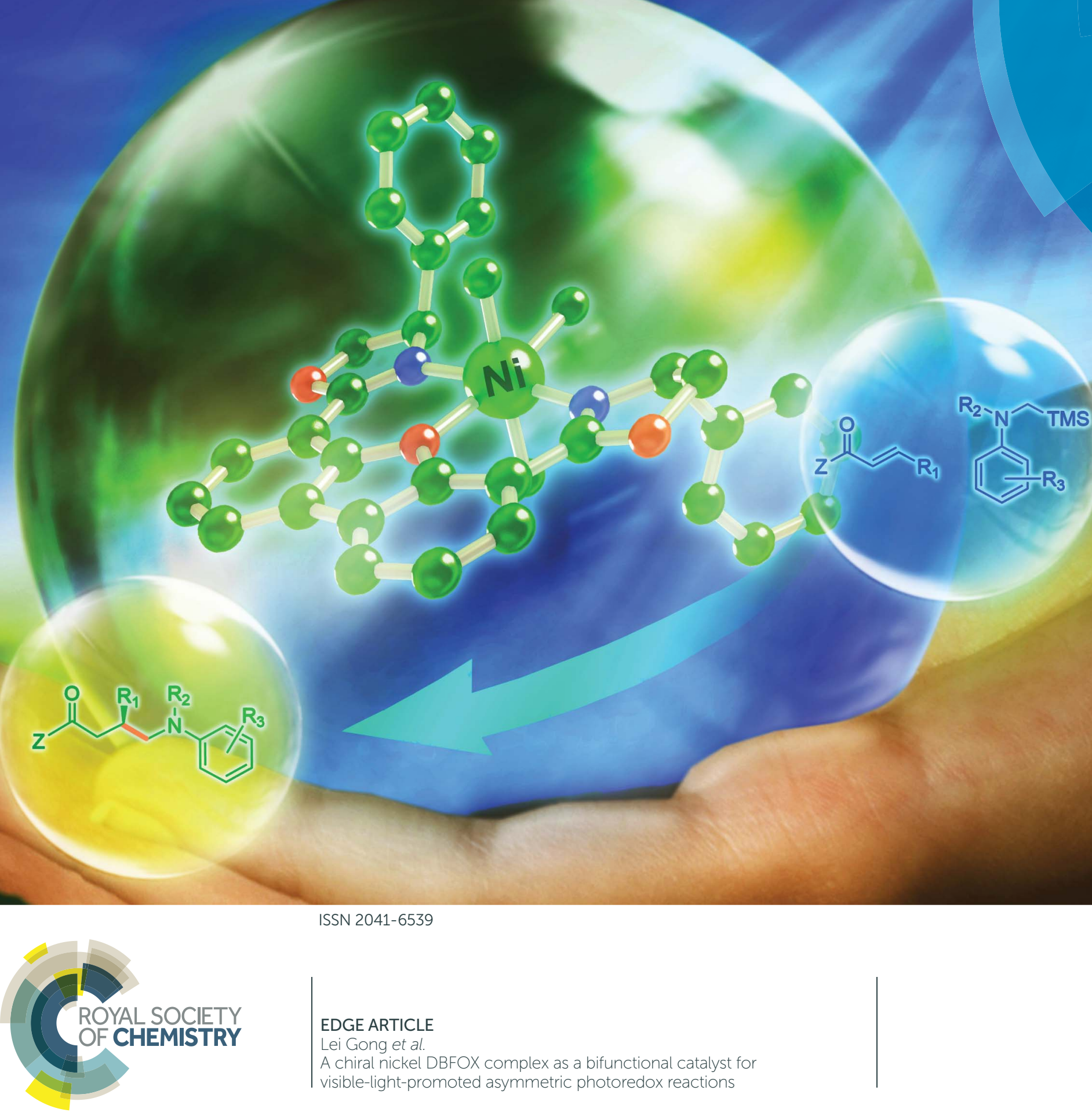
Check for updates

Cite this: Chem. Sci., 2018, 9, 4562

\title{
A chiral nickel DBFOX complex as a bifunctional catalyst for visible-light-promoted asymmetric photoredox reactions $\uparrow$
}

\author{
Xiang Shen, Yanjun Li, Zhaorui Wen, Shi Cao, Xinyi Hou and Lei Gong (DD* \\ The enantioselective photoredox reaction of $\alpha, \beta$-unsaturated carbonyl compounds and tertiary/secondary \\ $\alpha$-silylamines was enabled by a readily available single $\mathrm{Ni}^{\prime \prime}$-DBFOX catalyst (DBFOX $=4,6$-bis((R)-4-phenyl- \\ $4,5$-dihydrooxazol-2-yl)dibenzo[ $b, d]$ furan) under visible light conditions. The non-precious chiral catalyst is \\ involved in the photochemical process to initiate single electron transfer and at the same time provides \\ a well-organized chiral environment for the subsequent radical transformations. Good to excellent \\ enantioselectivities (80-99\% ee) were obtained for the formation of chiral $\gamma$-amino carboxylic acid \\ derivatives and $\gamma$-lactams.
}

Received 15th March 2018

Accepted 26th April 2018

DOI: $10.1039 / \mathrm{c} 8 \mathrm{sc} 01219 \mathrm{a}$

rsc.li/chemical-science

the radical generation and an additional chiral Lewis acid for controlling the stereoselective radical addition. Furthermore, the photocatalyst and the chiral Lewis acid often contain a precious metal. ${ }^{11,12}$ Using earth-abundant, first-row transition metal complexes instead as bifunctional single catalysts for asymmetric photoredox reactions opens a new avenue for cheap and green synthesis of chiral molecules, but this has been investigated much less. ${ }^{13}$ As the only established example, Fu's group demonstrated that a chiral copper complex can catalyze light-induced enantioselective $\mathrm{C}-\mathrm{N}$ cross-couplings, not only as the asymmetric catalyst but also as the precursor of the

erning the enantioselective conjugate addition of radicals produced by stoichiometric reduction of organic halides (Fig. 1a, left). ${ }^{4}$ These studies inspired chemists to develop cooperative chiral Lewis acid/photoredox catalytic systems for light-induced stereoselective radical transformations, providing a high level of asymmetric induction at mild and convenient reaction conditions (Fig. 1a, right). ${ }^{5-11}$ For instance, Yoon's group reported the first highly enantioselective intermolecular conjugate addition of $\alpha$-aminoalkyl radicals to $\alpha, \beta$-unsaturated carbonyl compounds by utilizing the combination of a chiral $\mathrm{Sc}^{\mathrm{III}}$ Lewis acid and $\mathrm{Ru}^{\mathrm{II}}$ tris-bipridine photocatalyst. ${ }^{6}$ Meggers et al. developed several chiral-at-metal rhodium complexes as chiral Lewis acids together with additional photocatalysts for highly enantioselective conjugate radical additions. ${ }^{7,8}$ The Kang group utilized a chiral-at-rhodium complex as a single catalyst for a catalytic asymmetric conjugate radical addition. ${ }^{9}$

Despite the impressive advances, typically two catalysts are required for this type of transformation: one photocatalyst for

Department of Chemistry, Key Laboratory of Chemical Biology of Fujian Province, iChEM, College of Chemistry and Chemical Engineering, Xiamen University, Xiamen, 361005, China.E-mail: gongl@xmu.edu.cn

† Electronic supplementary information (ESI) available. See DOI: 10.1039/c8sc01219a

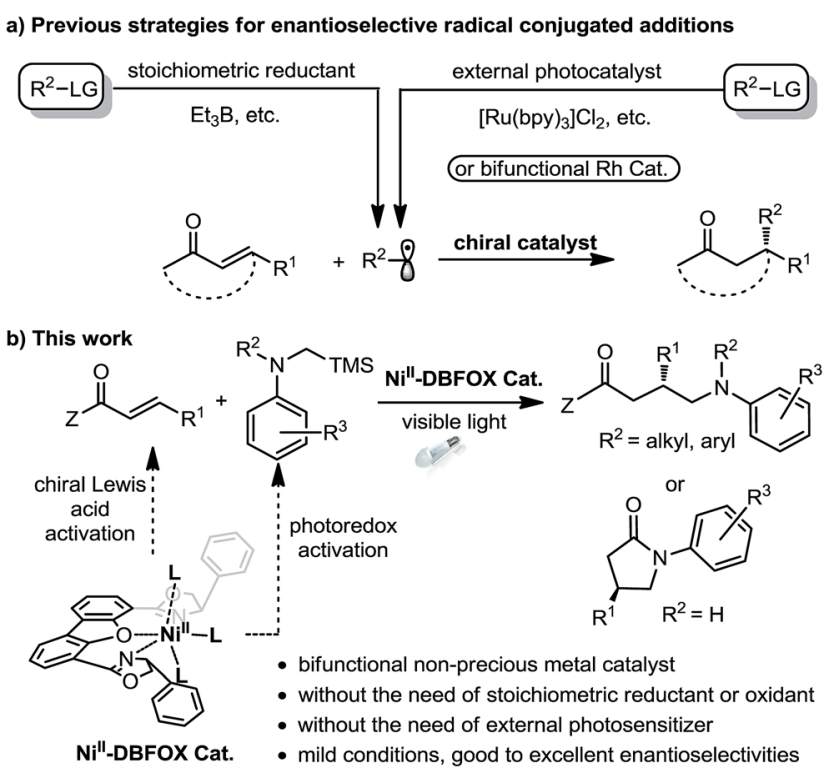

Fig. 1 Previous strategies for enantioselective radical conjugate additions and that developed in this study. 
photocatalyst. ${ }^{\mathbf{1 4}}$ Although they are inexpensive and wellcompatible in photochemical reactions, ${ }^{\mathbf{1 5}}$ nickel complexes themselves have only been reported as potential photoredox catalysts very recently. ${ }^{\mathbf{1 6 , 1 7}}$ Herein, we wish to reveal our discovery on using a readily available $\mathrm{Ni}^{\mathrm{II}}$-DBFOX complex as a bifunctional catalyst for visible-light-promoted enantioselective reactions between $\alpha, \beta$-unsaturated carbonyl compounds and $\alpha$-silylamines (Fig. 1b).

\section{Results and discussion}

Chiral $\mathrm{Ni}^{\mathrm{II}}$-DBFOX complexes have been used extensively in catalytic asymmetric nucleophilic additions, halogenation, cycloadditions and other transformations. ${ }^{18}$ Interestingly, we observed that one member of this class of complexes, Ni-L1, generated in situ by mixing $\mathrm{Ni}\left(\mathrm{ClO}_{4}\right)_{2} \cdot 6 \mathrm{H}_{2} \mathrm{O}$ and chiral DBFOX ligand $\mathbf{L 1}$ in a $1: 1$ ratio, exhibited obvious blue-green luminescence in THF (Fig. S5 in the ESI $\dagger$ ). In combination with its highly organized chiral environment and redox-active metal center, we envisioned that such a complex might be a potential candidate for asymmetric/photoredox bifunctional catalysis. ${ }^{19}$ With these considerations in mind, we commenced our study with $\alpha, \beta$-unsaturated crotonyl oxazolidinone $\mathbf{1 a}$ and tertiary $\alpha$ silylamine $\mathbf{2 a}$ as the model substrates. We here chose tertiary $\alpha$ silylalkylamines as the target substrate because they have low oxidation potentials (for example, $E_{\mathrm{ox}}\left(2 \mathrm{a}^{\cdot+} / \mathbf{2 a}\right)=+0.60 \mathrm{in}$ $\mathrm{CH}_{3} \mathrm{CN}$, Fig. S6 in the ESI $\dagger$ ) and are well-established to undergo single-electron oxidation followed by rapid desilylation to

Table 1 Initial experiments ${ }^{a}$
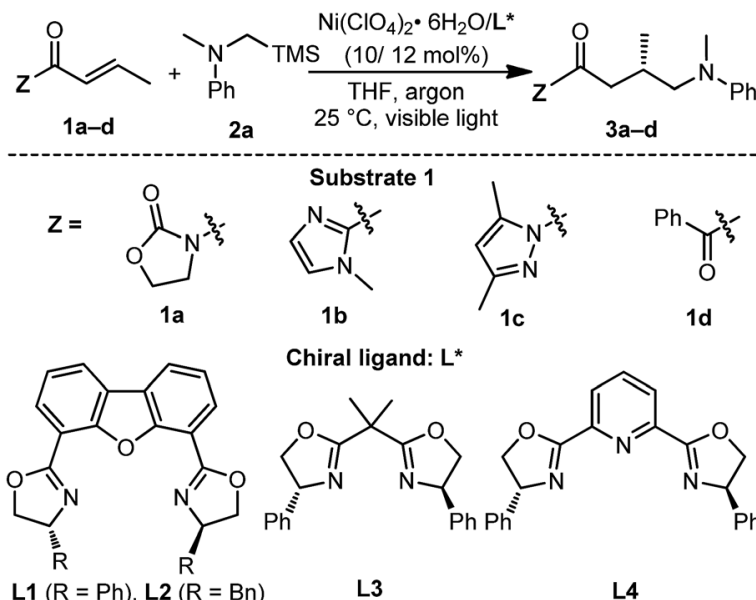

Chiral ligand: $L^{*}$

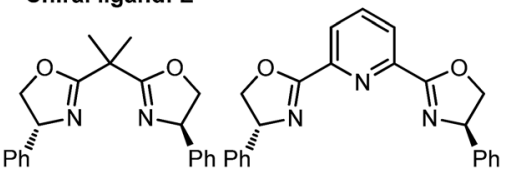

L4

\begin{tabular}{|c|c|c|c|c|c|c|c|c|}
\hline Entry & Substrate & Ligand & Light source & Additives & $t(\mathrm{~h})$ & Product & Conv. $^{b}(\%)$ & $\mathrm{ee}^{c}(\%)$ \\
\hline 1 & $1 a$ & L1 & White CFL & None & 12 & $3 a$ & 0 & n.a. \\
\hline 2 & $1 b$ & L1 & White CFL & None & 12 & $3 \mathbf{b}$ & 22 & 78 \\
\hline 3 & $1 \mathrm{c}$ & L1 & White CFL & None & 6 & $3 c$ & 95 & 91 \\
\hline 4 & $1 d$ & L1 & White CFL & None & 12 & $3 d$ & 0 & n.a. \\
\hline 5 & $1 \mathrm{c}$ & L2 & White CFL & None & 12 & $3 c$ & 23 & 0 \\
\hline 6 & $1 \mathrm{c}$ & L3 & White CFL & None & 12 & $3 c$ & 21 & n.d. \\
\hline 7 & $1 c$ & L4 & White CFL & None & 12 & $3 c$ & 0 & n.a. \\
\hline 8 & $1 c$ & L1 & Blue LEDs & None & 3 & $3 c$ & 95 & 91 \\
\hline 9 & $1 c$ & L1 & Red LEDs & None & 12 & $3 c$ & $<5$ & n.d. \\
\hline 10 & $1 c$ & L1 & Yellow LEDs & None & 12 & $3 c$ & 0 & n.a. \\
\hline 11 & $1 \mathrm{c}$ & L1 & UV (365 nm) & None & 6 & $3 c$ & 90 & 91 \\
\hline $12^{d}$ & $1 c$ & L1 & Blue LEDs & None & 12 & $3 c$ & 0 & n.a. \\
\hline $13^{e}$ & $1 c$ & $\mathbf{L 1}$ & Blue LEDs & None & 12 & $3 c$ & 0 & n.a. \\
\hline $14^{f}$ & $1 c$ & $\mathbf{L 1}$ & Blue LEDs & None & 12 & $3 c$ & 0 & n.a. \\
\hline 15 & $1 c$ & None & Blue LEDs & None & 12 & $3 c$ & 0 & n.a. \\
\hline 16 & $1 c$ & L1 & None & None & 12 & $3 c$ & $<5$ & n.a. \\
\hline $17^{g}$ & $1 c$ & $\mathbf{L 1}$ & Blue LEDs & None & 12 & $3 c$ & 0 & n.a. \\
\hline 18 & $1 c$ & L1 & Blue LEDs & 1 eq. TEMPO & 12 & $3 c$ & 0 & n.a. \\
\hline 19 & 1c & L1 & Blue LEDs & 3 eq. BHT & 12 & $3 c$ & 0 & n.a. \\
\hline
\end{tabular}

${ }^{a}$ Reaction conditions: 1a-d $(0.10 \mathrm{mmol}), \mathbf{2 a}(0.30 \mathrm{mmol}), \mathrm{Ni}\left(\mathrm{ClO}_{4}\right)_{2} \cdot 6 \mathrm{H}_{2} \mathrm{O}(10 \mathrm{~mol} \%)$, ligand L1-4 $(12 \mathrm{~mol} \%)$, THF $(0.50 \mathrm{~mL})$, indicated light source, $25{ }^{\circ} \mathrm{C}$, under argon; see more details of the screening of metal salts and solvents in the ESI. ${ }^{b}$ Conversion determined by ${ }^{1} \mathrm{H}-\mathrm{NMR}$. ${ }^{c}$ ee value determined by chiral HPLC. ${ }^{d}$ Reaction performed in the absence of nickel salt. ${ }^{e}$ Reaction performed by replacing $\mathrm{Ni}\left(\mathrm{ClO}_{4}\right)_{2} \cdot 6 \mathrm{H}_{2} \mathrm{O}$ with $\mathrm{Mg}(\mathrm{OTf})_{2} \cdot{ }^{f}$ Reaction performed by replacing $\mathrm{Ni}\left(\mathrm{ClO}_{4}\right)_{2} \cdot 6 \mathrm{H}_{2} \mathrm{O}$ with $\mathrm{Ni}(\mathrm{COD})_{2} \cdot{ }^{g}$ Reaction performed in air. n.d. $=$ not determined; n.a. $=$ not applicable. 
generate nucleophilic $\alpha$-aminoalkyl radicals. ${ }^{6,9}$ However, under irradiation with a $23 \mathrm{~W}$ white CFL lamp at $25{ }^{\circ} \mathrm{C}$ in the presence of premixed $10 \mathrm{~mol} \% \mathrm{Ni}\left(\mathrm{ClO}_{4}\right)_{2} \cdot 6 \mathrm{H}_{2} \mathrm{O}$ and $12 \mathrm{~mol} \% \mathrm{L1}$ in THF, no desired product 3a was observed (Table 1, entry 1 ). Next, we screened $\alpha, \beta$-unsaturated carbonyl compounds $\mathbf{1 b}-\mathbf{d}$ bearing different moieties adjacent to the carbonyl group (entries 2-4). To our delight, the reaction of $\alpha, \beta$-unsaturated imidazole $\mathbf{1 b}$ led to the formation of $\mathbf{3 b}$ in $22 \%$ conversion and with $78 \%$ ee (entry 2). Most interestingly, $\alpha, \beta$-unsaturated $N$-acyl pyrazole 1c provided significantly improved catalytic outcomes. Adduct 3c was afforded in 95\% conversion and with 91\% ee within only $6 \mathrm{~h}$ (entry 3). Other bisoxazoline ligands, L2-4, were also tested in the reaction, which, however, resulted in a much worse reaction rate and enantioselectivity (entries 5-7). The reaction was further improved by using a $24 \mathrm{~W}$ blue LED lamp, providing 3c in $95 \%$ conversion and with $91 \%$ ee in only $3 \mathrm{~h}$ (entry 8 ). Notably, when we replaced the blue LEDs with $30 \mathrm{~W}$ red or yellow LEDs, we failed to obtain the product (entries 9 and 10), while irradiation with a $15 \mathrm{~W}$ UV lamp (365 nm) still resulted in the production of $3 \mathbf{c}$ in good conversion and with high enantioselectivity (entry 11). These results indicate that the appropriate wavelength range of the light source is very critical for the transformation.

To obtain a better understanding of the system, several control experiments were conducted. As revealed by entries 1216, the nickel salt, DBFOX ligand L1, and visible light are all essential for the product formation. For example, after

a)

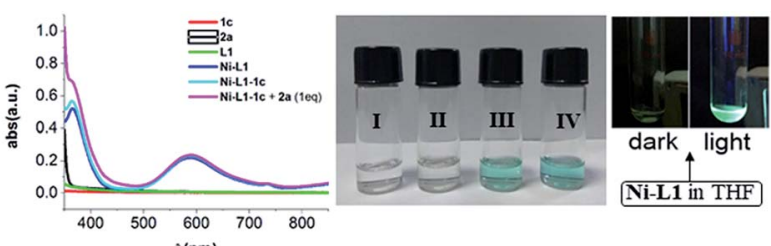

b)

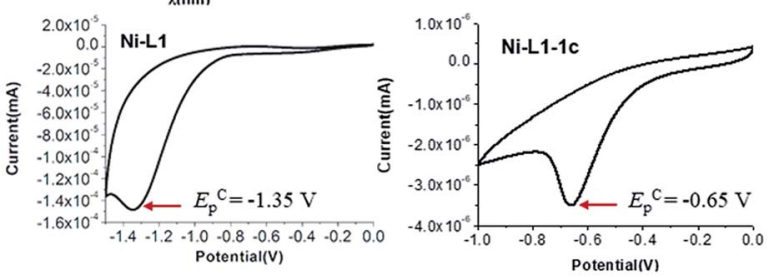

c)

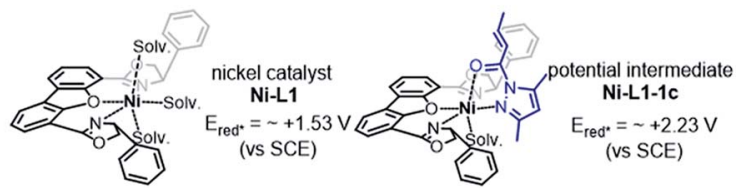

Fig. 2 (a) Left: UV-Vis absorption spectra recorded on a Shimadzu UV-2550 in a $10.0 \mathrm{~mm}$ quartz cuvette. Middle: I. Substrate $1 \mathrm{c}$ in THF $(0.030 \mathrm{M})$. II. Substrate $2 \mathrm{a}$ in THF $(0.030 \mathrm{M})$. III. Ni-L1 in THF (0.030 M). IV. Ni-L1-1c in THF (0.030 M). Right: A THF solution of nickel catalyst $\mathrm{Ni}-\mathrm{L} 1(0.030 \mathrm{M})$ in the dark and in the light. (b) Cyclic voltammogram of nickel catalyst $\mathrm{Ni}-\mathrm{L} 1(0.030 \mathrm{M})$ and potential intermediate complex $\mathrm{Ni}-\mathrm{L} 1-1 \mathrm{c}(0.030 \mathrm{M})$ in $\mathrm{TBAPF}_{6}(0.10 \mathrm{M})$ in $\mathrm{CH}_{3} \mathrm{CN}$. Sweep rate: $20 \mathrm{mV}$ $\mathrm{s}^{-1}$. A Pt electrode was used as the working electrode, a SCE as the reference electrode, and $\mathrm{Pt}$ wire as the auxiliary electrode. $E \mathrm{p}^{\mathrm{A}}$ is the anodic peak potential. $E_{p}^{C}$ is the cathodic peak potential. (c) Calculated reductive potentials of nickel catalyst $\mathrm{Ni}-\mathrm{L} 1$ and potential intermediate complex Ni-L1-1c in the excited states. removing $\mathrm{Ni}\left(\mathrm{ClO}_{4}\right)_{2} \cdot 6 \mathrm{H}_{2} \mathrm{O}$ (entry 12$)$ or replacing $\mathrm{Ni}\left(\mathrm{ClO}_{4}\right)_{2}$ $\cdot 6 \mathrm{H}_{2} \mathrm{O}$ with $\mathrm{Mg}(\mathrm{OTf})_{2}$ (entry 13), the reaction did not produce any desired product. Interestingly, the replacement of $\mathrm{Ni}^{\mathrm{II}}$ by $\mathrm{Ni}^{0}$ such as when using $\mathrm{Ni}(\mathrm{COD})_{2}$ as the metal source also led to failure in obtaining 3c, which indicates the possibility of nickel being involved in the redox process (entry 14). Moreover, air (entry 17), radical quencher TEMPO (entry 18) and BHT (entry 19) completely inhibited the transformation of $\mathbf{1 c}+\mathbf{2 a} \rightarrow \mathbf{3 c}$. These observations are consistent with a radical pathway.

Next, UV-Vis spectra were recorded to evaluate the light absorptions of the reaction components. The individual substrates 1c and 2a and the chiral ligand $\mathbf{L 1}$ do not feature any absorption in the visible light region, while a $1: 1$ mixture of $\left[\mathrm{Ni}\left(\mathrm{ClO}_{4}\right) \cdot 6 \mathrm{H}_{2} \mathrm{O}+\mathbf{L 1}\right]$ and $1: 1: 1$ mixture of $\left[\mathrm{Ni}\left(\mathrm{ClO}_{4}\right) \cdot 6 \mathrm{H}_{2} \mathrm{O}+\right.$ $\mathbf{L 1}+\mathbf{1 c}]$, leading to the in situ generation of the chiral nickel catalyst Ni-L1 and potential intermediate Ni-L1-1c respectively, exhibit significant absorption enhancement in the range of 400-450 nm (Fig. 2a). The broad peak at $\sim 600 \mathrm{~nm}$ is probably attributed to the nickel center. The spectroscopic analysis indicates that both Ni-L1 and Ni-L1-1c could be the potential photocatalysts. This conjecture was further strengthened by luminescence quenching experiments and Stern-Volmer quenching plots, which revealed obvious intermolecular interactions between Ni-L1 (or Ni-L1-1c) and 2a (Fig. S12-S15 in the $\mathrm{ESI} \dagger)$.

The cyclic voltammogram of $\alpha$-silylamine 2a exhibited an irreversible oxidation at $+0.60 \mathrm{~V}\left(E_{\mathrm{ox}}\left(2 \mathbf{a}^{\cdot+} / \mathbf{2 a}\right)\right)$ in $\mathrm{CH}_{3} \mathrm{CN}$ (Fig. S6 in the ESI $\dagger$ ), while those of Ni-L1 and Ni-L1-1c showed reductive peaks at $-1.35 \mathrm{~V}$ and $-0.65 \mathrm{~V}$ respectively (Fig. 2b),

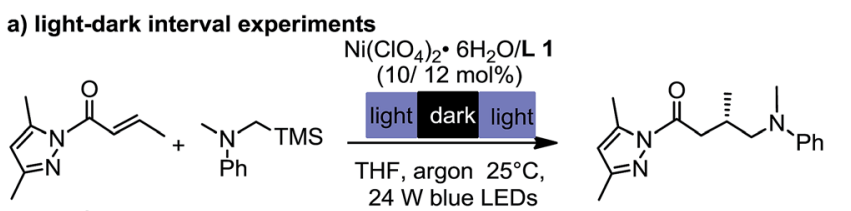

1c

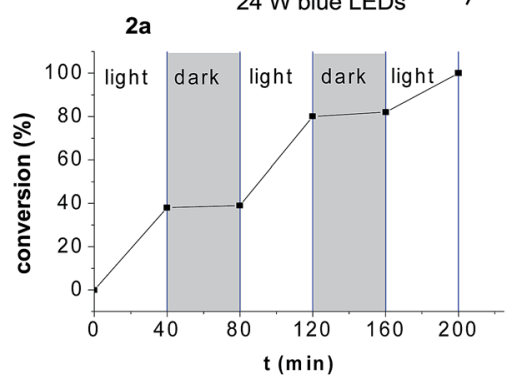

b) radical trapping experiment

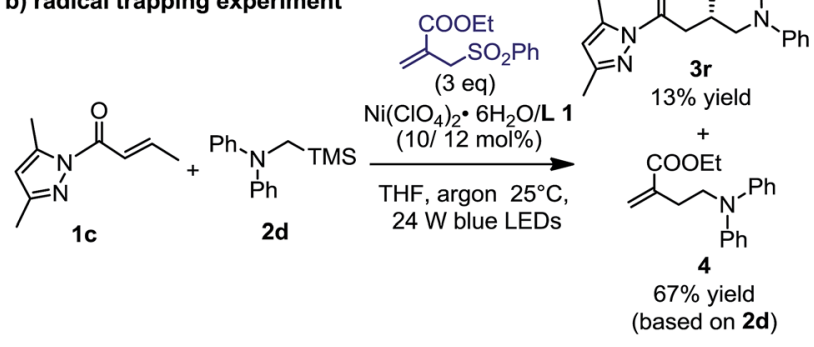

Fig. 3 Mechanistic investigation. (a) Intervals of irradiation and dark periods for the nickel-catalyzed reaction $1 c+2 a \rightarrow 3 c$. (b) Radical trapping experiment in the nickel-catalyzed reaction $1 c+2 d \rightarrow 3 r$. 
most likely corresponding to the reduction of $\mathrm{Ni}^{\mathrm{II}}$ to $\mathrm{Ni}^{\mathrm{I}}$. The excited-state potentials of the nickel complexes were further calculated by means of the Rehm-Weller formalism $\left(E\left(\mathrm{I}^{*} / \mathrm{I}^{{ }^{-}}\right)=\right.$ $\left.E\left(\mathrm{I} / \mathrm{I}^{\cdot-}\right)+E_{0,0}\left(\mathrm{I}^{*} / \mathrm{I}\right)\right) .^{19,20}$ Accordingly, $E_{\text {red }}^{*}\left([\mathbf{N i}-\mathbf{L 1}]^{*} /[\mathbf{N i}-\mathbf{L 1}]^{\cdot{ }^{-}}\right)$ was estimated to be $\sim+1.53 \quad \mathrm{~V}$, while $E_{\text {red }}^{*}\left([\mathbf{N i}-\mathbf{L 1}-\mathbf{1} \mathbf{c}]^{*} /[\mathbf{N i}-\mathbf{L 1}-\mathbf{1} \mathbf{c}]^{-}\right) \quad$ was estimated to be $\sim+2.23 \mathrm{~V}$ (Fig. 2c). Notably, the calculated reductive potential in the excited state of nickel catalyst $\mathbf{N i - \mathbf { L } 1}$ is comparable to that of a $\mathrm{Ni}^{\mathrm{II}}$ complex which was reported as a potential photoredox catalyst by Bach and Hess very recently. ${ }^{17 b}$ The electrochemical outcomes suggest that single electron transfer (SET) from the $\alpha$ silylamine $2 \mathrm{a}$ to the excited $\mathrm{Ni}^{\mathrm{II}}$ complexes was thermodynamically favorable.

Furthermore, the light-dark interval experiments revealed that continuous irradiation with visible light was essential for the reaction (Fig. 3a). The quantum yield $(\Phi)$ of the photochemical reaction was calculated to be 0.59 , suggesting that radical chain propagation would not be the predominant mechanism (see more details in Section 5.11 of the ESI $\dagger$ ). ${ }^{20}$ In addition, the reaction with the addition of 3 equiv. of ethyl 2((phenylsulfonyl)methyl)acrylate at the standard conditions led to the observation of product $3 \mathbf{r}$ in $13 \%$ yield and by-product 4 in $67 \%$ yield (Fig. $3 \mathrm{~b}$ ). Isolation of compound $\mathbf{4}$ further confirms the involvement of an $\alpha$-amino radical. The homolytic cleavage of $\alpha$-silylamine $2 \mathrm{a}$ by light was excluded by the photostability test (Fig. S16 in the ESI†).

On the basis of the initial experiments, mechanistic investigations and related literature, ${ }^{6,10}$ we propose a plausible reaction mechanism as depicted in Fig. 4. Accordingly, $N$-acyl pyrazole substrate $\mathbf{1}$ undergoes fast ligand exchange with the chiral nickel catalyst and affords the intermediate complex $\mathbf{A}$ (the above-mentioned potential intermediate Ni-L1-1). On the other hand, the photon-absorbing nickel complex Ni-L1 or NiL1-1 is activated by visible light, and then oxidizes $\alpha$-silylamine 2 by a single electron transfer to generate silylamine cation radical $\mathbf{B}$ and the reduced [Ni-L1] ${ }^{--}$(only Ni-L1 as the photocatalyst is shown in the figure). Subsequent desilylation of $\mathbf{B}$ led to the formation of the nucleophilic $\alpha$-aminoalkyl radical $\mathbf{C},{ }^{21,22}$ which undergoes radical addition to the $\mathrm{C}=\mathrm{C}$ double bond of

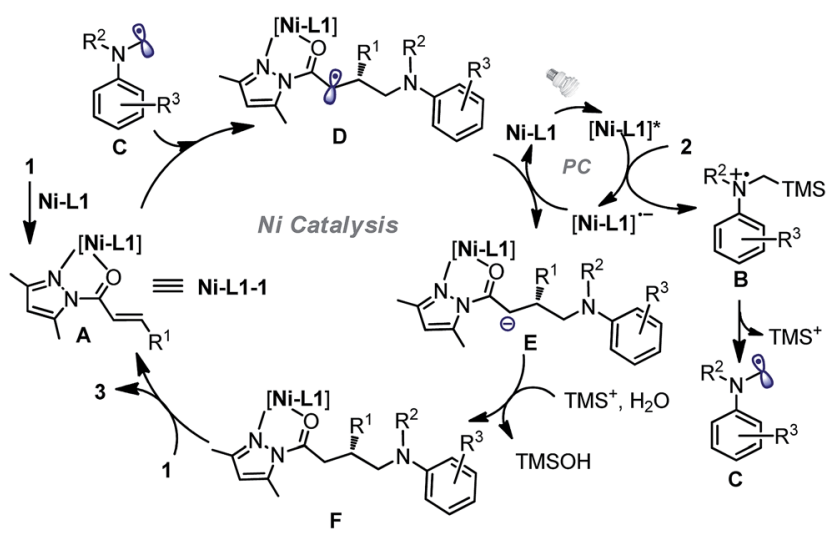

Fig. 4 A proposed reaction mechanism for the nickel-catalyzed enantioselective photoredox reaction of $\alpha, \beta$-unsaturated carbonyl compounds and $\alpha$-silylamines. complex $\mathbf{A}$ in an enantioselective fashion and transformation to radical species $\mathbf{D}$. Reduction of $\mathbf{D}$ by strong reductant [Ni-L1] ${ }^{\cdot-}$ produces anion $\mathbf{E}$, followed by protonation to afford neutral complex F. Finally, substitution with $\mathbf{1}$ released chiral product 3 and regenerated intermediate $\mathbf{A}$.

Considering the steric hindrance created by the tridentate and bidentate coordination, we assume that the nickel center does not interact directly with the free carbon radicals in the nickel catalysis cycle (Fig. 5). ${ }^{15}$ The metal instead serves as a Lewis acid to activate the electrophilic $N$-acyl pyrazole through a bidentate coordination. ${ }^{10,16}$ In the photocatalysis cycle, photon-absorbing nickel complex Ni-L1 or Ni-L1-1 participates in the light-induced single electron transfer process. It has to be mentioned that a radical coupling pathway involving a nickel enolate radical cannot be completely excluded (see more details in Section 5.10 of the ESI $\dagger$ ). ${ }^{7 c, 23}$ Concerning the stereochemistry, the proposed transition state is fully consistent with an observed $S$-configuration in the product (Fig. 5 ).

With the optimal conditions and better understanding of the reaction mechanism, we next evaluated the substrate scope of the nickel-catalyzed enantioselective photoredox reaction of $\alpha, \beta$-unsaturated carbonyl compounds and $\alpha$-silylamines. As

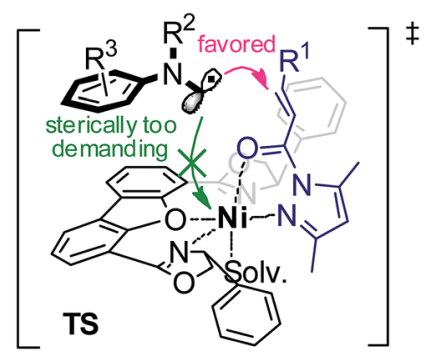

Fig. 5 proposed transition state for radical addition.
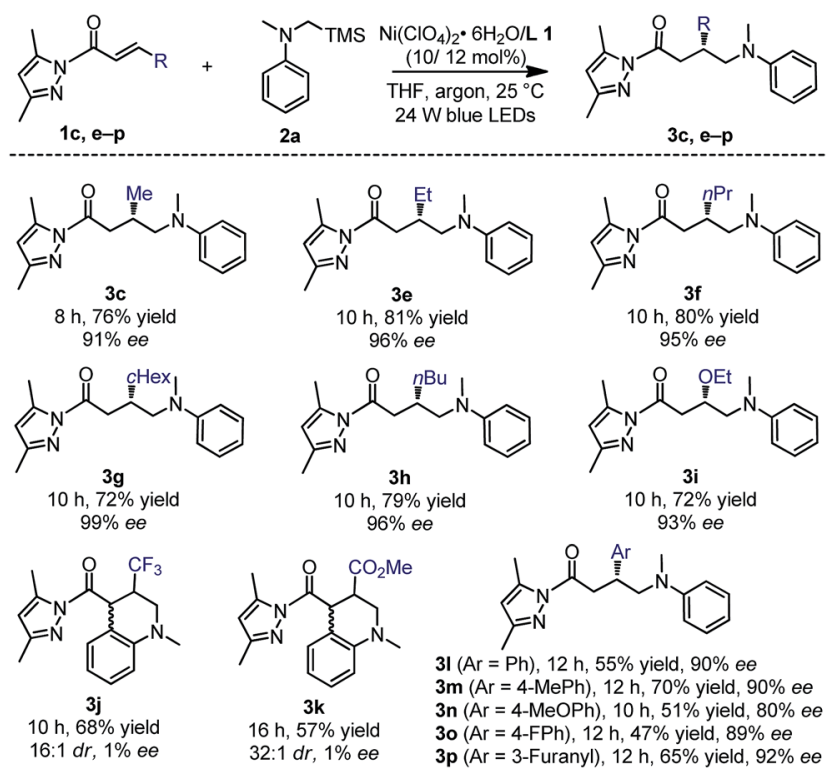

Fig. 6 Substrate scope with respect to $\alpha, \beta$-unsaturated $N$-acyl pyrazoles. 


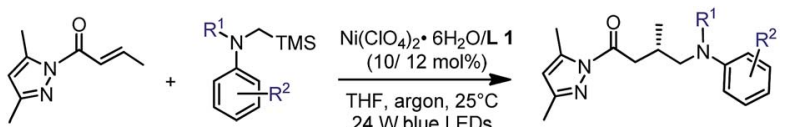

$16 \quad 24$ W blue LEDs $3 q-z a$
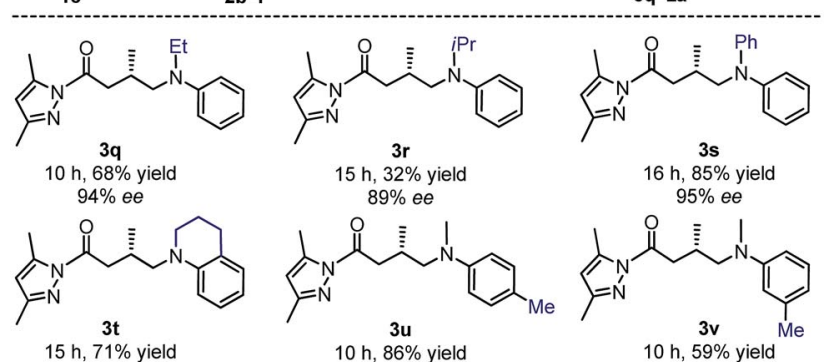

$16 \mathrm{~h}, 85 \%$ yield $95 \%$ ee
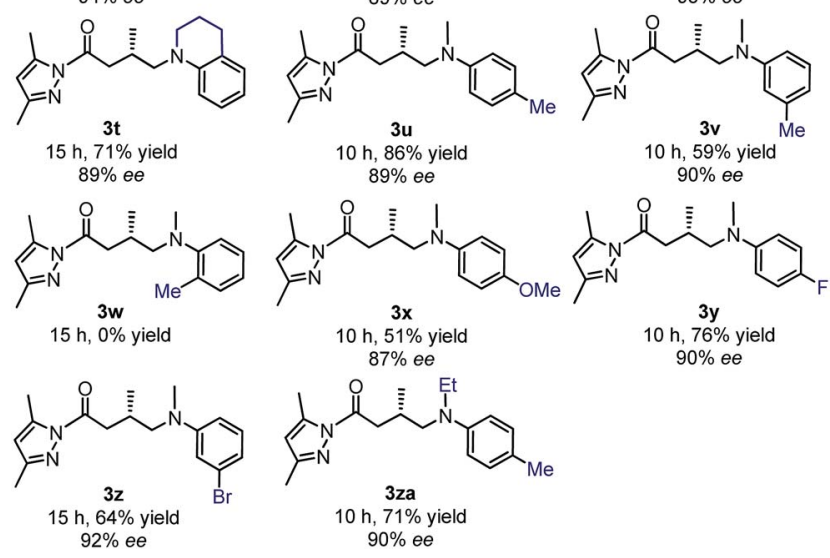

Fig. 7 Substrate scope with respect to tertiary $\alpha$-silylamines.

summarized in Fig. 6, a range of $\alpha, \beta$-unsaturated $N$-acyl pyrazoles containing aliphatic (products $\mathbf{3 c}$ and $\mathbf{e}-\mathbf{h}$ ), aromatic (products 31-p) or electron-donating (product 3i) substituents at the $\beta$-position were well tolerated. The products were obtained in $47-81 \%$ yields and with $80-99 \%$ ee. However, a strong electron-withdrawing $\beta-\mathrm{CF}_{3}$ or $\beta-\mathrm{CO}_{2} \mathrm{Me}$ substituent led to the further cyclized product $\mathbf{3 j}$ or $\mathbf{3 k}$. Although the yields and diastereoselectivities were good, the enantioselectivities were both

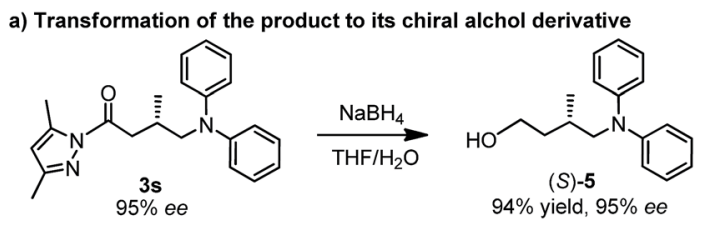

b) Reaction with secondary $\alpha$-silylamines to chiral $\gamma$-lactams
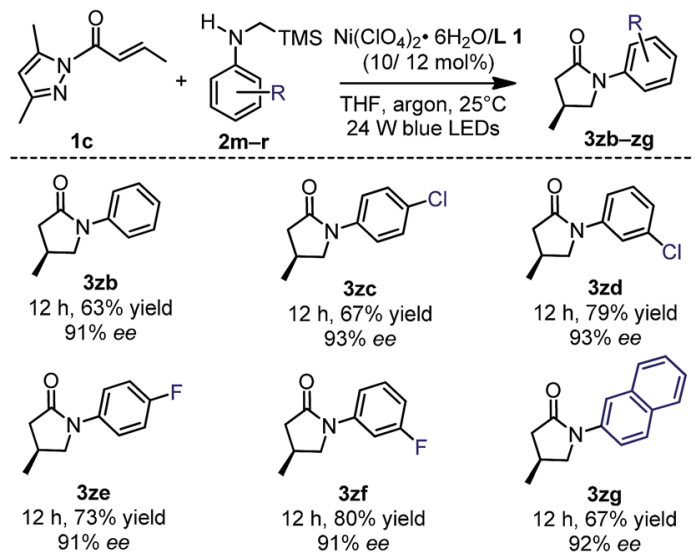

Fig. 8 Synthetic applications of the methodology. close to zero, which is most likely attributed to uncatalyzed background radical additions.

The tertiary $\alpha$-silylamines bearing more sterically demanding $N$-substituents (products $\mathbf{3 q - t}$ ), and electron donating $(3 \mathbf{u}-\mathbf{v})$ or withdrawing groups on the aniline moiety (3x-za) were also compatible (Fig. 7) with respect to the yields $(32-86 \%)$ and enantioselectivities $(87-95 \%$ ee). However, a methyl substituent in the 2-position of the aniline ring failed to provide the desired product $3 \mathbf{w}$, perhaps due to steric hindrance.

The $N$-acyl pyrazole moiety can be readily converted to a range of functional groups under mild conditions. ${ }^{24}$ As an example, the reaction of 3 s (95\% ee) with sodium borohydride in a $1: 1$ mixture of THF and water afforded the corresponding alcohol $(S)-5$ in a yield of $94 \%$ and with $95 \%$ ee (Fig. 8a). Accordingly, the absolute configuration of $3 \mathbf{s}$ was assigned as $S .^{6}$ More interestingly, if the tertiary $\alpha$-silylamines were replaced by secondary $\alpha$-silylamines in the nickel-catalyzed enantioselective photoredox reaction, further lactamization occurred to afford chiral $\gamma$-lactams (3zb-zg, 63-80\% yield, 91-93\% ee), one class of important building blocks in synthetic chemistry (Fig. 8b). ${ }^{25}$

\section{Conclusions}

In summary, we have revealed that a conventional $\mathrm{Ni}^{\mathrm{II}}$-DBFOX complex can effectively catalyze the asymmetric photoredox reaction between $\alpha, \beta$-unsaturated carbonyl compounds and tertiary/secondary $\alpha$-silylamines. As a bifunctional catalyst, the chiral nickel complex is not only involved in a photo-induced single electron transfer process to initiate the formation of the radical species, but also activates the $\alpha, \beta$-unsaturated carbonyl substrates as a Lewis acid and governs the radical transformation in an enantioselective fashion. Good to excellent yields and enantioselectivities were achieved for the chiral $\gamma$-amino carboxylic acid derivatives and $\gamma$-lactam products. In view of the non-precious, low-toxic metal salt, readily available chiral ligand, mild reaction conditions and high asymmetric induction, this strategy might provide new opportunities to develop cheap and green synthesis of chiral molecules. Further investigations of reaction mechanisms and applications of the catalytic system in asymmetric photoredox catalysis are ongoing in our laboratory.

\section{Conflicts of interest}

There are no conflicts to declare.

\section{Acknowledgements}

We gratefully acknowledge funding from the National Natural Science Foundation of China (grant no. 21572184 and 21472154), the Natural Science Foundation of Fujian Province of China (grant no. 2017J06006), and the Fundamental Research Funds for the Central Universities (grant no. 20720160027). We thank Dr Yan Liu and Mr Xu Yang of Xiamen University for their assistance in HRMS analysis. 


\section{Notes and references}

1 For selected reviews on visible-light photoredox catalysis, see: (a) J. M. R. Narayanam and C. R. J. Stephenson, Chem. Soc. Rev., 2011, 40, 102-113; (b) J. Xuan and W.-J. Xiao, Angew. Chem., Int. Ed., 2012, 51, 6828-6838; (c) L. Shi and W. Xia, Chem. Soc. Rev., 2012, 41, 7687-7691; (d) C. K. Prier, D. A. Rankic and D. W. C. MacMillan, Chem. Rev., 2013, 113, 5322-5363; (e) Y. Xi, H. Yi and A. Lei, Org. Biomol. Chem., 2013, 11, 2387-2403; (f) J. Xuan, L.-Q. Lu, J.-R. Chen and W.-J. Xiao, Eur. J. Org. Chem., 2013, 2013, 6755-6770; (g) M. Reckenthaeler and A. G. Griesbeck, Adv. Synth. Catal., 2013, 355, 2727-2744; (h) D. A. Nicewicz and T. M. Nguyen, ACS Catal., 2014, 4, 355-360; (i) S. Fukuzumi and K. Ohkubo, Org. Biomol. Chem., 2014, 12, 6059-6071; (j) R. A. Angnes, Z. Li, C. R. D. Correia and G. B. Hammond, Org. Biomol. Chem., 2015, 13, 9152-9167; (k) J.-R. Chen, X.-Q. Hu, L.-Q. Lu and W.-J. Xiao, Chem. Soc. Rev., 2016, 45, 2044-2056; (l) J. Zhu, W.-C. Yang, X.-D. Wang and L. Wu, Adv. Synth. Catal., 2018, 360, 386-400.

2 A. G. Amador and T. P. Yoon, Angew. Chem., Int. Ed., 2016, 55, 2304-2306.

3 For recent reviews on asymmetric photoredox catalysis, see: (a) R. Brimioulle, D. Lenhart, M. M. Maturi and T. Bach, Angew. Chem., Int. Ed., 2015, 54, 3872-3890; (b) E. Meggers, Chem. Commun., 2015, 51, 3290-3301; (c) Z.-Y. Cao, W. D. G. Brittain, J. S. Fossey and F. Zhou, Catal. Sci. Technol., 2015, 5, 3441-3451; (d) C. Wang and Z. Lu, Org. Chem. Front., 2015, 2, 179-190; (e) H. Huo and E. Meggers, Chimia, 2016, 70, 186-191; (f) E. Meggers, Angew. Chem., Int. Ed., 2017, 56, 5668-5675.

4 (a) J. H. Wu, G. R. Zhang and N. A. Porter, J. Am. Chem. Soc., 1995, 117, 11029-11030; (b) M. P. Sibi and J. Ji, J. Am. Chem. Soc., 1996, 118, 9200-9201; (c) J. H. Wu, G. R. Zhang and N. A. Porter, Tetrahedron Lett., 1997, 38, 2067-2070; (d) N. A. Porter, H. Feng and I. K. Kavrakova, Tetrahedron Lett., 1999, 40, 6713-6716; (e) M. P. Sibi, J. Ji, J. B. Sausker and C. P. Jasperse, J. Am. Chem. Soc., 1999, 121, 7517-7526; (f) M. Murakata, H. Tsutsui and O. Hoshino, Org. Lett., 2001, 3, 299-302; $(g)$ M. P. Sibi and J. Chen, J. Am. Chem. Soc., 2001, 123, 9472-9473; (h) M. P. Sibi and S. Manyem, Org. Lett., 2002, 4, 2929-2932; (i) M. P. Sibi, J. Zimmerman and T. Rheault, Angew. Chem., Int. Ed., 2003, 42, 4521-4523; (j) G. K. Friestad, Y. Shen and E. L. Ruggles, Angew. Chem., Int. Ed., 2003, 42, 5061-5063; ( $k$ ) M. P. Sibi, G. Petrovic and J. Zimmerman, J. Am. Chem. Soc., 2005, 127, 2390-2391; (l) S. Lee, C. J. Lim, S. Kim, R. Subramaniam, J. Zimmerman and M. P. Sibi, Org. Lett., 2006, 8, 4311-4313; (m) M. P. Sibi and J. Zimmermann, J. Am. Chem. Soc., 2006, 128, 1334613347; (n) M. P. Sibi, Y.-H. Yang and S. Lee, Org. Lett., 2008, 10, 5349-5352; for an account, see: (o) M. P. Sibi and N. A. Porter, Acc. Chem. Res., 1999, 32, 163-171.

5 For leading reviews on dual catalysis by combining photoredox with organo-, acid, and transition-metal catalysis, see: (a) M. N. Hopkinson, B. Sahoo, J.-L. Li and F. Glorius, Chem.-Eur. J., 2014, 20, 3874-3886; (b)
T. P. Yoon, Acc. Chem. Res., 2016, 49, 2307-2315; (c) K. L. Skubi, T. R. Blum and T. P. Yoon, Chem. Rev., 2016, 116, 10035-10074.

6 L. R. Espelt, I. S. McPherson, E. M. Wiensch and T. P. Yoon, J. Am. Chem. Soc., 2015, 137, 2452-2455.

7 (a) H. Huo, K. Harms and E. Meggers, J. Am. Chem. Soc., 2016, 138, 6936-6939; (b) C. Y. Wang, K. Harms and E. Meggers, Angew. Chem., Int. Ed., 2016, 55, 13495-13498; (c) J. Ma, X. Xie and E. Meggers, Chem.-Eur. J., 2018, 24, 259-265.

8 For a recent account, see: L. Zhang and E. Meggers, Acc. Chem. Res., 2017, 50, 320-330.

9 S.-X. Lin, G.-J. Sun and Q. Kang, Chem. Commun., 2017, 53, 7665-7668.

10 J. Liu, W. Ding, Q.-Q. Zhou, D. Liu, L.-Q. Liu and W.-J. Xiao, Org. Lett., 2018, 20, 461-464.

11 For a sophisticated bifunctional Lewis acid/photocatalyst, see: H. Huo, X. Shen, C. Wang, L. Zhang, P. Röse, L.-A. Chen, K. Harms, M. Marsch, G. Hilt and E. Meggers, Nature, 2014, 515, 100-103.

12 For selected examples of merging photoredox catalysis with asymmetric organocatalysis, see: (a) D. A. Nicewicz and D. W. C. MacMillan, Science, 2008, 322, 77-80; (b) M. Neumann, S. Füldner, B. König and K. Zeitler, Angew. Chem., Int. Ed., 2011, 50, 951-954; (c) K. Fidaly, C. Ceballos, A. Falguières, M. S.-I. Veitia, A. Guy and C. Ferroud, Green Chem., 2012, 14, 1293-1297; (d) D. A. DiRocco and T. Rovis, J. Am. Chem. Soc., 2012, 134, 8094-8097; (e) L. J. Rono, H. G. Yayla, D. Y. Wang, M. F. Armstrong and R. R. Knowles, J. Am. Chem. Soc., 2013, 135, 17735-17738; (f) Y. Zhu, L. Zhang and S.-Z. Luo, J. Am. Chem. Soc., 2014, 136, 14642-14645; (g) P. Riente, A. M. Adams, J. Albero, E. Palomares and M. A. Percàs, Angew. Chem., Int. Ed., 2014, 53, 9613-9616; (h) G. Bergonzini, C. S. Schindler, C.-J. Wallentin, E. N. Jacobsen and C. R. J. Stephenson, Chem. Sci., 2014, 5, 112-116; (i) G. Wei, C. Zhang, F. Bures, X. Ye, C.-H. Tan and Z. Jiang, ACS Catal., 2016, 6, 3708-3712; (j) E. Larionov, M. M. Mastandrea and M. A. Pericàs, ACS Catal., 2017, 7, 7008-7013.

13 A. Gualandi, M. Marchini, L. Mengozzi, M. Natali, M. Lucarini, P. Ceroni and P. G. Cozzi, ACS Catal., 2015, 5, 5927-5931.

14 Q. M. Kainz, C. D. Matier, A. Bartoszewicz, S. L. Zultanski, J. C. Peters and G. C. Fu, Science, 2016, 351, 681-684.

15 For selected examples, see: (a) J. C. Tellis, D. N. Primer and G. A. Molander, Science, 2014, 345, 433-436; (b) C. P. Johnston, R. T. Smith, S. Almendinger and D. W. C. MacMillan, Nature, 2016, 536, 322-325; (c) D. R. Heitz, J. C. Tellis and G. A. Molander, J. Am. Chem. Soc., 2016, 138, 12715-12718; (d) B. Shields and A. G. Doyle, J. Am. Chem. Soc., 2016, 138, 12719-12722; (e) Z. Zuo, H. Cong, W. Li, J. Choi, G. C. Fu and D. W. C. MacMillan, J. Am. Chem. Soc., 2016, 138, 18321835; (f) P. Zhang, C. C. Le and D. W. C. MacMillan, J. Am. Chem. Soc., 2016, 138, 8084-8087; (g) S. Zheng, D. N. Primer and G. A. Molander, ACS Catal., 2017, 7, 7957-7961; (h) C. Remeur, C. B. Kelly, N. R. Patel and 
G. A. Molander, ACS Catal., 2017, 7, 6065-6069; (i) K. Lin, R. J. Wiles, C. B. Kelly, G. H. M. Davies and G. A. Molander, ACS Catal., 2017, 7, 5129-5133; (j) X. Zhang and D. W. C. MacMillan, J. Am. Chem. Soc., 2017, 139, 11353-11356; ( $k$ ) H. Huang, X. Li, C. Yu, Y. Zhang, P. S. Mariano and W. Wang, Angew. Chem., Int. Ed., 2017, 56, 1500-1505; (l) D. N. Primer and G. A. Molander, J. Am. Chem. Soc., 2017, 139, 9847-9850.

16 For a recent study on a nickel complex containing a visiblelight-responsive chiral ligand for metal-photocatalytic asymmetric aerobic oxidation reaction, see: W. Ding, L.-Q. Lu, Q.-Q. Zhou, Y. Wei, J.-R. Chen and W.-J. Xiao, J. Am. Chem. Soc., 2017, 139, 63-66.

17 For two very recent studies on establishing nickel(II) complexes as the potential visible-light photocatalyst, see: (a) B. J. Shields, B. Kudisch, G. D. Scholes and A. G. Doyle, J. Am. Chem. Soc., 2018, 140, 3035-3039; (b) M. Grübel, I. Bosque, P. J. Altmann, T. Bach and C. R. Hess, Chem. Sci., 2018, 9, 3313-3317.

18 For selected examples, see: (a) S. Kanemasa, Y. Oderaotoshi, S.-i. Sakaguchi, H. Yamamoto, J. Tanaka, E. Wada and D. P. Curran, J. Am. Chem. Soc., 1998, 120, 3074-3088; (b) K. Itoh and S. Kanemasa, J. Am. Chem. Soc., 2002, 124, 13394-13395; (c) N. Shibata, J. Kohno, K. Takai, T. Ishimaru, S. Nakamura, T. Toru and S. Kanemasa, Angew. Chem., Int. Ed., 2005, 44, 4204-4207; (d) I. Kennosuke, H. Masayuki, T. Junji and K. Shuji, Org. Lett., 2005, 7, 979-981; (e) J. Esquivias, R. G. Arrayás and J. C. Carretero, J. Am. Chem. Soc., 2007, 129, 1480-1481; (f) T. Ishimaru, S. Ogawa, E. Tokunaga, S. Nakamura and N. Shibata, J. Fluorine Chem., 2009, 130, 1049-1053; $(g)$
D. S. Reddy, N. Shibata, T. Horikawa, S. Suzuki, S. Nakamura, T. Toru and M. Shiro, Chem.-Asian J., 2009, 4, 1411-1415; (h) D. S. Reddy, N. Shibata, J. Nagai, S. Nakamura and T. Toru, Angew. Chem., Int. Ed., 2009, 48, 803-806; (i) X. Yang, F. Cheng, Y.-D. Kou, S. Pang, Y.-C. Shen, Y.-Y. Huang and N. Shibata, Angew. Chem., Int. Ed., 2017, 56, 1510-1514.

19 T. C. Jenks, M. D. Bailey, J. L. Hovey, S. Fernando, G. Basnayake, M. E. Cross, W. Li and M. J. Allen, Chem. Sci., 2018, 9, 1273-1278.

20 (a) E. Arceo, I. D. Jurberg, A. Álvarez-Fernández and P. Melchiorre, Nat. Chem., 2013, 5, 750-756; (b) M. Silvi, C. Verrier, Y. P. Rey, L. Buzzetti and P. Melchiorre, Nat. Chem., 2017, 9, 868-873.

21 For a recent account on synthetic utilization of $\alpha$-aminoalkyl radicals in visible-light photoredox catalysis, see: K. Nakajima, Y. Miyake and Y. Nishibayashi, Acc. Chem. Res., 2016, 49, 1946-1956.

22 For a perspective concerning practicality and chemoselectivity of radical transformations, see: M. Yan, J. C. Lo, J. T. Edwards and P. S. Baran, J. Am. Chem. Soc., 2016, 138, 12692-12714.

23 M. P. DeMartino, K. Chen and P. S. Baran, J. Am. Chem. Soc., 2008, 130, 11546-11560.

24 L. Feng, X. Dai, E. Meggers and L. Gong, Chem.-Asian J., 2017, 12, 963-967.

25 For representative reviews, see: $(a)$ C. Nájera and M. Yus, Tetrahedron: Asymmetry, 1999, 10, 2245-2303; (b) S. Hanessian and L. Auzzas, Acc. Chem. Res., 2008, 41, 1241-1251; (c) A. Stefanucci, E. Novellino, R. Costante and A. Mollica, Heterocycles, 2014, 89, 1801-1825. 